\title{
RECENSÃO
}

\author{
Book review
}

\section{TEIXEIRA, Patrícia Brito. Caiu na rede. E agora: gestão e gerenciamentos de crises nas redes sociais. São Paulo: Évora, 2013. 168 p. ISBN978-85-63993-52-6.}

Com o advento da Internet, estamos expostos permanentemente uns aos outros em maior ou menor grau, indivíduos e organizações. Tendemos, em muitas ocasiões, a acentuar apenas as vantagens e as oportunidades que as ferramentas de comunicação possibilitam. Estamos, majoritariamente, no deslumbramento e no encantamento com aquilo que esses recursos já nos oferecem, ao mesmo tempo em que estamos tentando descobrir todas as possibilidades de usos e benefícios que podem permitir que desenvolvamos. Lembrando a autora, estamos na fase da disputa do espaço no palco sem nos apercebermos do telhado de vidro.

Assim, no primeiro capítulo, a autora, ao abordar o tema da Opinião Pública, enfatiza que, com o advento e disseminação da Internet, todos - pessoas e empresas, assim como instituições e órgãos governamentais - têm uma visibilização e um risco de crise crescentes. As esferas públicas, restritas a grupos de proximidade e de interesses imediatos se multiplicam e ampliam através das redes sociais, num multiverso de mídias por sua vez voltadas para objetivos e focos específicos, como os blogs, o facebook, o linkedin, o twitter, apenas para mencionar alguns. Os órgãos de imprensa e de comunicação tradicionais alimentam essas redes e, por sua vez, são abastecidos por elas, num processo de convergência de mídias.

Os indivíduos se tornam cada vez mais sujeitos da comunicação, partilhando informações e registros que antes ficavam restritos a quem estivesse próximo dos acontecimentos ou participasse de determinado

\begin{tabular}{|l|l|l|l|l|l|}
\hline Teocomunicação & Porto Alegre & v. 44 & n. 3 & p. 438-442 & set.-dez. 2014 \\
\hline
\end{tabular}


debate circunstanciado. As causas de minorias ou de excluídos do acesso à grande mídia ganham oportunidade de entrarem nos debates e nos projetos, permitindo voz e vez a quem em outras circunstâncias não as teriam.

Naturalmente, isso constitui também uma grande oportunidade para as organizações divulgarem seus produtos e serviços. No entanto, oportunidades que exigem redobrada atenção em relação à qualidade e à idoneidade dos produtos e serviços oferecidos, um cuidado para que as informações divulgadas sejam corretas e estrategicamente construídas, além da atenção constante que se faz necessário dispensar aos comentários e observações que a opinião pública vai construindo, zelando, dessa forma, para que as mensagem e notícias positivas nela ecoem, nas diferentes esferas públicas.

No segundo capítulo, Patrícia foca a crise na perspectiva dos conceitos e dos impactos sobre as organizações. Inicia com alguns exemplos e com a etimologia da palavra crise para chamar a atenção de que ela significa uma ameaça à organização, mas pode significar também oportunidade, a depender das ações e das atitudes encaminhadas.

As crises podem ser de muitas naturezas, variando conforme o tamanho e o tipo de produtos ou serviços ofertados. Certamente, um olhar apenas voltado para a produção, o incentivo ao consumo e a busca por lucros em muitos casos pode desencadear crises relacionadas ao meio ambiente, como poluição, destruição de biossistemas e efeito estufa, assim como mão de obra escrava e subassalariado, desvios éticos de várias ordens, dentre outros, além de riscos financeiros numa economia cada vez mais globalizada. Internamente, uma gestão descuidada aumenta o risco a partir de falhas humanas e técnicas dentro dos processos de produção e da prestação de serviços de qualidade.

O preparo para detectar ameaças de crise e administrá-las antes que eclodam se torna cada vez mais uma questão-chave. Uma vez estabelecida a crise e em sendo encarada como de interesse de todos ou de muitos, a esfera pública torna-se o espaço do debate e do embate de posições, de pontos de vista, objetivando soluções e alternativas com o propósito de minimizar riscos futuros. Na sociedade de risco, cabe sempre o engajamento de todos na busca por soluções para minimizar ou prevenir riscos, para assim evitar crises, como tarefa de todos, especialistas ou não.

Não prestar atenção aos pequenos sinais de que algo não está bem, ou é percebido como sendo pelos interessados, é criar condições 
para que uma crise se estabeleça. Com a internet, as pessoas tendem a compartilhar sua insatisfação com pessoas das suas relações que, por sua vez, também as compartilham, conferindo à divulgação uma proporção geométrica. Um simples fato pode transformar-se num acontecimento, à medida que for tendo repercussão e novos desdobramentos vierem à tona e o número de pessoas envolvidas ou afetadas for aumentando.

Mesmo sabendo que ninguém consegue agradar a todos, é necessário perseguir permanentemente a satisfação do maior número possível de "clientes", mapear os motivos de insatisfações, investir na melhoria dos produtos e serviços, acompanhados de um relacionamento eficiente e transparente com os públicos também pela internet como "parte da identidade corporativa e, por consequência, da construção da imagem e da reputação da marca" (p. 45).

No terceiro capítulo, sob o título Construção de identidade, imagem e reputação na internet, a autora começa observando, a partir de Mário Rosa que, quanto mais conhecida a empresa e quanto mais credibilidade tiver, mais estará exposta a riscos. A confiança, calcada na identidade da empresa, como expressão de todos os processos produzidos internamente e externamente comunicados, gera a imagem corporativa, enquanto reflexo da identidade: "imagem é o que passa na mente dos públicos; é o imaginário e as percepções das pessoas" (p. 54). Por fim, a reputação, é o resultado da imagem que se sedimenta ao longo do tempo e cuja solidez depende do alinhamento da identidade e da imagem da organização.

$\mathrm{Na}$ sequência, a autora insiste na necessidade da construção de uma comunicação organizacional integral e a apresenta constituída pelo diagnóstico, análise do diagnóstico, mapeando os problemas da organização: análise de mercado, definição de metas, objetivos, estratégias e plano de ação. Chama a atenção que, para cada público, deve ser direcionada uma ação específica, pois as linguagens e as mensagens e, inclusive, os meios de comunicação são diferentes.

Por último, neste capítulo, lembra que, nas ocasiões de crise, a boa reputação se torna um crédito conquistado por meio de uma comunicação consolidada junto aos públicos e a importância de, em caso de crise, na era digital, a organização se manifestar dentro do período de uma hora. Por isso, a importância da comunicação digital estar inserida na comunicação organizacional, em vista do alinhamento estratégico no plano global de comunicação da organização. 
O tema do quarto capítulo trata da aprendizagem com os erros, lembrando que essa ocorre com a própria experiência e das lições que podemos tirar de crises enfrentadas por outros. A autora passa, então, a analisar e a comentar diversos episódios de crises ocorridas em época recente. Conclui apresentando dez dicas do que se pode ou deve aprender com crises como essas.

No quinto capítulo, o título é uma advertência: Sua empresa pode ser a vítima da próxima crise. Prevenir-se a crise é de fundamental importância; saber o que fazer se ela acontecer precisa estar previsto, através de uma eficiente gestão de crise para um gerenciamento eficaz. Assim, apresenta alguns passos: o Issue Management, um processo de mapeamento das condições da empresa, no concernente à análise de risco, cultura organizacional, posicionamento no ambiente on-line, a comunicação aplicada, one off-line, com os diferentes públicos, as atitudes éticas, a análise dos produtos e serviços, dos fornecedores, dentre outros itens percebidos como relevantes. A seguir fala da prevenção como empenho para que em todos os ambientes e níveis da empresa se tomem sempre as medidas necessárias para que tudo esteja certo, do treinamento de pessoal à verificação da procedência da matériaprima. No item Planejamento, destaca a importância da comunicação estratégica digital, o monitoramento da marca nas redes sociais, com um profissional capacitado, a criação do comitê de crise, a definição do porta-voz e a criação do manual de crise on-line. Conclui o capítulo com um Roteiro de orientação para este Planejamento e com Dicas de gestão de crise para evitar danos à imagem da marca ou amenizar os impactos causados, sugeridos por Regina Barros.

O sexto capítulo trata do que fazer durante uma crise, sob o título Uma crise foi desencadeada. E agora? Inicialmente, retoma a diferenciação entre gestão e gerenciamento de crise e o desespero que muitas vezes acompanha as organizações na ausência do planejamento. Lista sinais indicadores do início de uma crise nas redes sociais. Alerta de que o processo de mapeamento das vulnerabilidades precisa ser constante e contínuo. Reforça a importância da tomada de providências imediatas. Qualquer demora é danosa. Redigir relatórios minuciosos da crise para posterior análise e implantação de medidas para que não se repita. $\mathrm{Na}$ continuidade do capítulo, é apresentada uma listagem dos processos que compreendem o gerenciamento de crise, seguido da indicação de comportamentos e atitudes adequados para o gerenciamento de crise na internet. 
O sétimo capítulo, com o título Pós-crise: conquiste a sua reputação, reforça que é preciso trabalhar com estratégia para conquistar o relacionamento com o público para recuperar a imagem e ter certeza de que o episódio está superado, recuperando os créditos perdidos na reputação. A autora sugere e descreve diversos passos: a análise da crise; o monitoramento das redes sociais; mediante o método da análise de conteúdo e do método da análise retórica; a análise de crise nas redes sociais: e o Relatório de crise, para o qual sugere um roteiro. Para concluir, aborda a comunicação pós-crise, observando que "cada comunicação deve estar alinhada e direcionada ao público ao qual se destina, a fim de garantir sua efetividade e resultado para o emissor" (p. 130).

Por último, nas considerações finais, reforça que pensar estrategicamente inclui reconhecer que toda organização tem riscos, empenha-se em saber como preveni-los e, em caso de crise, saber o que fazer. Conclui o livro com um Roteiro contemplando a Gestão de Crise, o Gerenciamento da Crise e o Pós-Crise.

Parece-me que a abordagem no livro vai além do que o título sugere: a rede é um dos temas abordados, um espaço importante, atual e cada vez mais amplamente presente e acessível a pessoas das diferentes camadas sociais e graus de escolaridade, mas, mesmo assim, um espaço a mais, ao lado de outros igualmente importantes e com repercussão significativa a favor ou contra pessoas, organizações ou órgãos governamentais. O grande desafio é desenvolver uma consciência crescente da responsabilidade em relação à qualidade e procedência dos produtos e serviços oferecidos, a honestidade e a transparência nas informações prestadas, no conjunto das relações estabelecidas com os diferentes públicos de interesse, no Planejamento, na Gestão e no gerenciamento da crise, caso ocorra, e na aprendizagem com a mesma.

José Romaldo Klering*

\footnotetext{
* Professor e Coordenador do Departamento de Cultura Religiosa da Faculdade de Teologia da PUCRS. Mestre em Teologia e Doutor em Educação pela PUCRS. E-mail: <jose.klering@pucrs.br>.
} 